\title{
Políticas para a formação de professores e as recomendações do Banco Mundial: interfaces com o contexto atual da formação de professores alfabetizadores no Brasil
}

\section{Policies for teacher education and recommendations of the World Bank: interfaces with the current context of literacy teacher education in Brazil}

\section{Políticas de formación docente y recomendaciones del Banco Mundial: interfaces con el contexto actual de la formación de maestros de alfabetización en}

\author{
Jani Alves da Silva Moreira* \\ Renata Valério da Silva**
}

\begin{abstract}
Resumo: O objetivo deste artigo é analisar as recomendações do Banco Mundial e sua relação com as políticas de formação de professores no Brasil, a fim de identificar as consonâncias com as atuais políticas para a formação de professores no contexto da alfabetização. Trata-se de uma análise documental, de cunho teórico-crítico, a qual permitiu observar que as atuais políticas para formação de professores estão em consonância com as recomendações do Banco Mundial. Tais orientações geram a atribuição aos professores da responsabilidade pelo sucesso ou fracasso escolar dos alunos, verificados por meio de avaliações externas com base no desempenho avaliado. Palavras-chave: Formação de professores. Políticas educacionais. Banco Mundial.
\end{abstract}

\begin{abstract}
The purpose of this paper is to analyze the recommendations of the World Bank and its relation to the policies of teacher education in Brazil, in order to identify the concordances between current policies for teacher education in the literacy context. This is a document analysis of theoretical and critical nature, which permitted to observe that current policies for teacher education are consistent with the recommendations of the World Bank. Such guidelines generate the allocation of responsibility to the teachers for the success or failure of school students, verified through external assessments and based on the assessed performance.
\end{abstract}

Keywords: Teacher education. Education policies. World Bank.

\footnotetext{
*Professora da Universidade Estadual de Maringá (UEM). E-mail: <professorajani@hotmail.com>

** Pedagoga do Colégio Dom Bosco de Maringá. E-mail: <ree3_@hotmail.com>
} 
Resumen: El objetivo de este artículo es analizar las recomendaciones del Banco Mundial y su relación con la política de formación docente en Brasil, con el fin de identificar las consonancias con las políticas actuales para la formación docente en el contexto de la alfabetización. Se trata de un análisis documental de carácter teórico y crítico, que permitió observar que las políticas actuales para la formación docente son consistentes con las recomendaciones del Banco Mundial. Tales directrices generan la atribución a los docentes de la responsabilidad por el éxito o el fracaso escolar de los estudiantes, verificado a través de evaluaciones externas con base en el desempeño evaluado.

Palabras clave: Formación Docente. Políticas Educativas. Banco Mundial.

\section{Introdução}

Este artigo é resultado da pesquisa de Iniciação Científica intitulada "A influência do banco mundial nas políticas de formação e valorização de professores no Brasil"' e tem por objetivo analisar as recomendações do Banco Mundial (BM) no que concernem às políticas de formação de professores. Tais recomendações foram verificadas nas análises de enunciados e discursos do Banco Mundial, especificamente em dois documentos: Prioridades y Estrategias para la Educacion (BANCO MUNDIAL, 1995) e Mejorar la enseñanza y el aprendizaje por medio de incentivos: Qué lecciones nos entregan lãs reformas educativas de América Latina? (BANCO MUNDIAL, 2005). A seleção de tais documentos se justifica por dois motivos: a) Tratam da temática formação de professores; b) Foram publicados, respectivamente, na última década do século XX e a primeira década deste século XXI, o que favorece a comparação com as recomendações do BM indicadas no decênio. Além desses documentos do BM, estudamos leis e documentos oficiais que abordam essa temática com o intuito foi de observar os processos de regulação das políticas no que tangem à concretização ou não da recomendação sugerida pela agência com o fito de destacar suas interfaces, ou seja, as relações e interconexões com a atual política de formação de professores, particularmente a política de formação desenvolvida no Programa Pacto Nacional pela Alfabetização na Idade Certa (2013-2014).

Para dar conta do proposto, apresentamos, inicialmente, uma exposição das origens do BM e de suas finalidades e atuação no cenário educacional. Em seguida,

\footnotetext{
${ }^{1}$ Parte dos resultados apresentados neste artigo são decorrentes da Pesquisa de Iniciação Científica (PIC/ UEM) realizada em 2012 e que, posteriormente, se configurou em uma análise documental de textos oriundos do Banco Mundial no trabalho final de conclusão do curso de Pedagogia da Universidade Estadual de Maringá em 2014.
} 
discorremos sobre os documentos do BM referenciados, com destaque para as orientações em relação à política de formação e valorização de professores. Por fim, ponderamos acerca de algumas questões relativas às políticas desenvolvidas no Brasil para a formação e valorização de professores de alfabetização considerando as interfaces com as orientações do BM.

\section{Banco Mundial (BM): histórico e atuação}

A partir da década de 1990, no Brasil, estudos que contemplam a influência das organizações e organismos internacionais no processo de definição e concretização das políticas educacionais no Brasil são crescentes. Atribui-se esse crescimento à necessidade de compreensão do contexto denominado "consolidação do consenso" (SHIROMA; MORAES; EVANGELISTA, 2002), o que pode ser nomeado como um processo de consolidação da regulação internacional na construção de uma agenda política mundial para a educação.

$\mathrm{Na}$ análise da influência das orientações do BM na definição e construção de uma agenda política voltada à formação de professores no Brasil, ancoramo-nos na abordagem metodológica intitulada por Dale (2004) de Agenda Globalmente Estruturada para a Educação (AGEE). Na visão deste autor, a compreensão do processo de construção e consolidação de uma política para a educação recebe contornos e processos de regulação tais que no contexto de mundialização do capital são considerados forças supranacionais:

[...] uma nova forma de força supranacional afecta os sistemas educativos nacionais [...] como é que os estados interpretam e respondem a uma agenda comum que esta abordagem propõe estar a ser imposta sobre os sistemas educativos. E ainda compreender as [...] novas concepções sobre a natureza das forças globais e sobre como é que elas operam, e atribui estas transformações à mudança da natureza das forças supranacionais, não estando os valores culturais universais e os guiões imunes às forças da globalização, económica, política e cultural. (DALE, 2004, p. 454-455).

Nas análises aqui mediadas, consideramos que as políticas educacionais são compreendidas diante das relações supranacionais. Verificamos que o Estado promove a legitimação das práticas neoliberais de governança, acumulação e de controle social na construção da política de governança da educação (MOREIRA, 2012). Todavia, essa legitimação se concretiza no bojo do metabolismo de uma relação na qual os países poderão consentir ou não. Em conformidade com esse encaminhamento de análise, Teodoro (2008, p. 23) assegura que:

[...] o recurso ao estrangeiro funciona, prioritariamente, como um elemento de legitimação de opções assumidas no plano nacional, e muito pouco como um esforço sério de um conhecimento contextualizado de outras experiências 
e de outras realidades. Mas, simetricamente, pode-se também considerar que as constantes iniciativas, estudos e publicações das organizações internacionais desempenham um decisivo papel na normalização das políticas educativas nacionais, estabelecendo uma agenda que fixa não apenas prioridades, mas igualmente as formas como os problemas se colocam e equacionam, e que constituem uma forma de fixação de um mandato, mais ou menos explícito conforme a centralidade dos países.

O BM, como uma agência multilateral da Organização das Nações Unidas (ONU), atua como consultor técnico e financiador de projetos na área da educação. Criado em 1944 na Conferência Monetária e Financeira das Nações Unidas chamada de Bretton Woods ${ }^{2}$, é atualmente composto por um conjunto de agências, sendo elas:

[...] BIRD (Banco Internacional para Reconstrução e Desenvolvimento), que abrange quatro outras agências: a IDA (Associação Internacional de Desenvolvimento), a IFC (Corporação Financeira Internacional), a ICSID (Centro Internacional para Resolução de Disputas sobre Investimentos) e a MIGA (Agência de Garantia de Investimentos Multilaterais). (SOARES, 1998, p. 16).

A criação desse grupo vincula-se à fundação do Fundo Monetário Internacional (FMI), e ambas as instituições surgiram com o objetivo de solucionar os problemas econômicos oriundos do pós-Segunda Guerra Mundial (1939-1945) e evitar novas crises internacionais.

Ao longo dos 50 anos de existência, o BM ganhou caráter de um banco voltado para o financiamento de projetos aos países em desenvolvimento, que se encontram em contínuo processo de avanço econômico. Visando promover o crescimento desses países, iniciou-se, em 1968, a gestão McNamara ${ }^{3}$. Essa administração ficou marcada por uma redistribuição dos empréstimos com a finalidade de alavancar a economia e erradicar a pobreza desses países; para tanto, o investimento no setor da agricultura ganhou ênfase. Fonseca (1998, p.230) explica que "[...] o setor social, incluindo a educação, que até então não era privilegiada no projeto de financiamento do Banco, passou a ter acesso aos créditos dessa agência”.

\footnotetext{
${ }^{2}$ Nome pelo qual ficou conhecida a Conferência Monetária e Financeira das Nações Unidas realizada em julho de 1944, em Bretton Woods (New Hampshire, EUA), com representantes de 44 países, para planejar a estabilidade da economia internacional e das moedas nacionais prejudicadas pela Segunda Guerra Mundial. Os acordos assinados em Bretton Woods tiveram validade para o conjunto das nações capitalistas lideradas pelos Estados Unidos, resultando na criação do Banco Internacional para a Reconstrução e Desenvolvimento (BIRD). (SANDRONI, 1985, p. 83).

${ }^{3}$ Robert McNamara é “[...] ex-aluno da Havard Business School e ex-presidente da Ford Motor Company. Ocupava o cargo de secretário de Defesa dos EUA desde 1961 quando foi guindado pela Casa Branca para a presidência do Banco Mundial. [...] deu início à sua gestão em abril de 1968 [...]. O símbolo mais forte dessa atuação [...] era a promoção do desenvolvimento e crescimento econômico, melhoria dos indicadores sociais básicos e redução da desigualdade socioeconômica. McNamara deixou a presidência do Banco Mundial em 1981, um ano antes do estouro da crise da dívida externa" (PEREIRA, 2010, p. 36).
} 
Na década de 1980, houve uma crise mundial que acarretou o endividamento dos países que recebiam empréstimos do BM devido à superprodução de mercadorias e ao baixo fluxo de movimento dessas. Naquele contexto, o papel do BM se reestruturou por meio de estratégias e programas de ajuste estrutural ${ }^{4}$. A dívida externa do Brasil estava em um estado grave: o país já não exportava tanto e as taxas de importações eram muito elevadas; tendo em vista essa crise de endividamento , o BM impôs programas de estabilização e ajuste na economia brasileira.

Com a implantação desses programas, o grupo passou a intervir de maneira direta na economia brasileira, formulando políticas de economia interna, influenciando sobremaneira nas determinações legais. O BM transformou-se então em uma espécie de "guardião", o que se responsabilizava pela dívida externa dos países em desenvolvimento para com seus credores; nesse caso, os líderes da economia mundial. O BM não só se responsabilizava pelo pagamento da dívida como também por adequar e integrar os países em desenvolvimento ao capital globalizado, mediante a abertura do mercado econômico. (TOMMASI, 1998).

É importante destacar que os empréstimos concedidos pelo BM não constituem doações nem políticas econômicas de favorecimento ao desenvolvimento das nações. A esse respeito, Fonseca (1998, p. 234) sustenta que:

Embora a política de crédito do Banco se autodenomine "cooperação" ou "assistência técnica", trata-se, na verdade, de empréstimos do tipo convencional (ou hard), tendo em vista os pesados encargos que acarretam e também a rigidez das regras e as pré-condições financeiras e políticas inerentes ao processo de financiamento comercial.

Por meio dos empréstimos e, consequentemente, dos acordos estabelecidos para a sua concessão o BM passou a controlar as políticas dos países em desenvolvimento e atuar de maneira direta na reestruturação desses países. No início dos anos 1990, o Brasil assinou seu primeiro acordo de estabilização com o FMI, se enquadrando, assim, às exigências do BM, as quais, por seu turno, eram essencialmente políticas de ajuste. O grupo cedia os empréstimos e decidia as porcentagens destinadas a cada setor.

Os projetos financiados pelo Banco Mundial dividem-se em setores como agricultura, energia, transporte, finanças, desenvolvimento urbano, saúde e nutrição e educação. O BM não é apenas o financiador desses setores. No caso do setor educacional, é também quem dita as metas que devem ser atingidas.

\footnotetext{
${ }^{4}$ Programas de ajuste estrutural são reformas orientadas para o mercado, que têm como objetivo a "[...] diminuição do papel do Estado - privatizações, demissões, desregulamentação das relações trabalhistas, terceirizações, diminuição da carga tributária; abertura econômica e comercial - livre trânsito para o capital financeiro e abertura dos mercados" (CARDOZO, 2005, p. 3).
} 
Torres (1998) assevera que o BM estimula os países a intensificar os recursos públicos no setor da educação básica, pois considera que esse setor é fundamental para o desenvolvimento econômico sutentável a longo prazo, visando amenizar os problemas com a pobreza. Segundo o autor, ao formular pacotes de medidas que devem ser implantados nos países em desenvolvimento, o BM procede de uma maneira geral; suas medidas são políticas que contemplam os aspectos da educação, indo desde as macropolíticas até medidas que devem ser tomadas em sala de aula, no cotidiano escolar.

Em 1995, o BM publicou um de seus primeiros documento na área da educação. Intitulado Prioridades y Estrategias para la Educacion, apontou mudanças que considera significativas para o setor da educação, entre as quais:

1. Dar más prioridad a la educaión. 2. Prestar más atención a los resultados. 3. Centrar La inversión pública em La enseñanza básica, recurriendo al mismo tiempo em mayor medida AL financiamiento familiar para La enseñanza superior. 4. Prestar más atención a la equidad. 5. Dar más participación al grupo familiar. 6. Dar más autonomia a las instituciones. (BANCO MUNDIAL, 1995, p. XXII-XXVI) ${ }^{5}$.

O documento aborda a educação básica como essencial para o funcionamento da sociedade com o fito de proporcionar conhecimentos, habilidades e competências aos sujeitos. No entanto, esse discurso do BM, que culminou com a publicação desse documento, repercutiu no Brasil com a ênfase no Ensino Fundamental, especificamente nas séries iniciais.

Em 1995, o discurso do BM era de que tão importante quanto investir na educação básica é também investir no profissional que nela atua, pontuando a relevância de o professor ter o domínio de conteúdo. Além disso, necessitam-se de professores capacitados e qualificados para atuar em sala de aula, e para atingir a esse objetivo, "[...] consiste en contratar personal debidamente capacitado cuyos conocimientos se hayan evaluado" (BANCO MUNDIAL, 1995, p. 91).

De acordo com a legislação brasileira, a contratação de professores da rede pública se dá por meio de concursos públicos. Para atuar na Educação Básica, existem requisitos obrigatórios estabelecidos no Artigo 61 da Lei de Diretrizes e Bases no 9.394/1996:

Art. 61. Consideram-se profissionais da educação escolar básica os que, nela estando em efetivo exercício e tendo sido formados em cursos reconhecidos, são:

\footnotetext{
${ }^{5} 1$ Dar mais prioridade à educação; 2 Dar mais atenção aos resultados; 3 Centralizar o investimento público na educação básica, recorrendo, ao mesmo tempo, no desempenho do ensino superior; 4 Prestar mais atenção à equidade; 5 Aumentar a participação do grupo familiar; 6 Dar mais autonomia para as instituições. (BANCO MUNDIAL, 1995, p. XXII-XXVI, tradução nossa).
} 
I - professores habilitados em nível médio ou superior para a docência na educação infantil e nos ensinos fundamental e médio;

II - trabalhadores em educação portadores de diploma de pedagogia, com habilitação em administração, planejamento, supervisão, inspeção e orientação educacional, bem como com títulos de mestrado ou doutorado nas mesmas áreas;

III - trabalhadores em educação, portadores de diploma de curso técnico ou superior em área pedagógica ou afim.

Parágrafo único. A formação dos profissionais da educação, de modo a atender às especificidades do exercício de suas atividades, bem como aos objetivos das diferentes etapas e modalidades da educação básica, terá como fundamentos:

I - a presença de sólida formação básica, que propicie o conhecimento dos fundamentos científicos e sociais de suas competências de trabalho;

II - a associação entre teorias e práticas, mediante estágios supervisionados e capacitação em serviço;

III - o aproveitamento da formação e experiências anteriores, em instituições de ensino e em outras atividades. (BRASIL, 1996a).

Pontuamos que a atual LDB atual assegura a contratação desses profissionais, mas apenas isso não garante professores qualificados para atuarem no ambiente escolar. O conceito de qualificação mescla-se com o conceito de formação inicial. Salientamos a necessidade de se fazer valer a lei no que tocante à formação de professores, visando à garantia de uma política nacional que favoreça a qualificação do professor no processo de formação inicial e continuada em instituições de Ensino Superior (IES) no país que sejam bem avaliadas e desenvolvam um currículo de formação de maneira adequada e coerente. Evidentemente, faz-se necessária uma política de formação de professores que acompanhe e forneça as mudanças necessárias na formação desenvolvida nos cursos de licenciatura, das IES públicas e privadas, nos cursos presenciais e a distância.

\section{As políticas de formação de professores e as recomendações do Banco Mundial}

Os documentos publicados pelo BM têm por finalidade nortear os países que se utilizam dos empréstimos desse órgão. Em 1995, o documento "Prioridades y Estrategias para la Educación” teve por objetivo orientar os responsáveis pelas políticas públicas nos países, especialmente aqueles responsáveis pelo sistema de alocação dos recursos públicos para a educação. (BANCO MUNDIAL, 1995).

Esse documento aborda ainda medidas que abrangem aspectos da educação; nele consta que para haver uma reforma educacional é necessário se iniciar pela 
gestão, ou seja, é preciso gerenciar os recursos recebidos de modo que todos os campos da educação sejam contemplados. Conforme análise do BM, o gerenciamento desses recursos encontra como barreira situações como o não adequado regime de colaboração entre os governos municipal, estadual e federal, pois estes distribuem os recursos e os investe de maneira não unânime. O BM é inflexível em relação à má gestão da educação em países cujos governos não dirigem a educação de maneira igualitária. Outro ponto observado no discurso do BM é sobre a centralidade; enunciados do documento afirmam que os governos se dedicam ora para solucionar os problemas de um campo da educação, como o "salário dos professores", ora para solucionar os problemas encontrados nas "reformas educacionais", existindo a centralidade e não a totalidade, e as medidas não são tomadas para contemplar todos os campos e sim pontos específicos. (BANCO MUNDIAL, 1995).

Ainda nesse documento, evidencia-se a urgência da reforma educativa para a solução dos problemas que impedem o desenvolvimento da educação. $\mathrm{O}$ documento elenca os pontos principais que carecem de prioridade, tais como "acesso", "qualidade", "equidade", "aceleração das reformas". Enfatiza também a importância da distribuição equitativa dos recursos destinados à educação. Portanto, não traz como foco principal o professor. Entretanto, devido à impossibilidade de separar o professor do processo educativo, é inevitável que sejam contempladas questões sobre esse profissional.

No discurso do BM (1995), uma educação de eficácia envolve diretamente a distribuição de recursos,

La mayoría de los sistemas de educacíon son administrados directamente por el gobierrno central o estatal, que dedica un esfuerzo considerable a ocuparse de cuestiones como la negociacíon de los salarios de los maestros, los programas de construccíon de escuelas y la reforma de los planes de estudio. (BANCO MUNDIAL, 1995, p. 5). ${ }^{6}$

Atrelado a recomendação da distribuição de recursos, encontra-se uma orientação política para a gestão flexível que direciona à necessidade de investir na capacitaqção de professores, a estratégia mais eficaz para o desenvolvimentos da educação é a contratação de professores que dominam suas áreas de conhecimentos e tenham formação suficiente para ensinar e transmitir o conhecimento. (BANCO MUNDIAL, 1995, p. 8).

$\mathrm{Na}$ perspectiva do BM, os professores devem ser avaliados para ingressar na carreira docente por meio de provas de conhecimento, que avaliem o co-

\footnotetext{
${ }^{6}$ A maioria dos sistemas de ensino é administrada diretamente pelo governo central ou estadual, que dedica um esforço considerável para abordar questões como a negociação de salários de professores, programas de construção de escolas e da reforma curricular. (BANCO MUNDIAL, 1995, p. 5, tradução nossa).
} 
nhecimento teórico do professor sobre determinados assuntos. Aqueles que se destacam, teoricamente, são os que estão mais aptos a assumir uma sala de aula. Os conhecimentos são adquiridos por meio de estudo, e por isso o BM defende que para se tornar um profissional eficiente é necessária uma formação completa e continuada. (BANCO MUNDIAL, 1995).

Aumentar o total de alunos por professor, segundo o discurso do BM, implica em uma melhoria para a educação: "Las escuelas de los países de ingreso bajo y mediano podrían ahorrar costos y mejorar el aprendizaje aumentando el coeficiente profesor-alumnos. Utilizarían así menos maestros y podrían asignar los recursos a otros insumos que mejoran el rendimiento [...]"” (BANCO MUNDIAL, 1995, p. 85).

Juntamente com o aumento do número de alunos em sala de aula por professor, introduz-se, nas orientações do BM, a discussão sobre a autonomia do professor. No documento, consta que o professor precisa ter autonomina quanto ao desenvolvimento de suas aulas, mas para isso precisa seguir um "un plan de estudio nacional", isto é, as diretrizes que norteiam a educação. E para dar suporte a essa autonomia, tanto do professor em sala de aula quanto das escolas, no que tange, respectivamente, aos recursos didáticos e financeiros, pontua que "[...] entre las medidas financieras para fomentar la autonomía y la responsabilidad de las escuelas y las instituciones cabe citar las siguientes: el uso de impuestos locales y centrales [...]"8 (BANCO MUNDIAL, 1995, p. 34).

No Brasil, a LDB no 9.394/96 prevê que as instituições públicas são mantidas com recursos públicos, logo, o salário dos professores também, como explicita seu Artigo 68:

Serão recursos públicos destinados à educação os originários de: I - receita de impostos próprios da União, dos Estados, do Distrito Federal e dos Municípios; II - receita de transferências constitucionais e outras transferências; III - receita do salário-educação e de outras contribuições sociais; IV - receita de incentivos fiscais; $\mathrm{V}$ - outros recursos previstos em lei. (BRASIL, 1996a).

Dessa forma, as medidas que aparecem nos documentos publicados pelo Banco Mundial estão a concretizar-se por meio de leis e projetos no Brasil. Assim, como as recomendações do BM não deixam claro e tampouco garantem uma política de salários justa aos professores, nossa legislação também caminha na mesma direção.

\footnotetext{
${ }_{7}^{7}$ Escolas de países de renda baixa e média poderiam economizar custos e melhorar a aprendizagem, aumentando a relação professor-aluno. E os recursos gastos com os professores diminuiriam assim os recursos podem ser alocados para outros insumos que melhoram o desempenho, tais como livros didáticos e formação de professores em serviço. (BANCO MUNDIAL, 1995, p. 85, tradução nossa).

${ }^{8}$ Entre as medidas financeiras para promover a autonomia e responsabilização das escolas e instituições incluem o seguinte: o uso de impostos locais e centrais. (BANCO MUNDIAL, 1995, p. 34, tradução nossa).
} 
Após dez anos da publicação do documento de 1995, o documento Mejorar la enseñanza y el aprendizaje por medio de incentivos, de 2005, apresenta como tema principal o professor, sua importância e os incentivos que este deve receber como forma de valorização. Conceitua a palavra incentivo como "[...] algo que despierta um sentimiento o incita a la acción; uma causa o motivo de entusiasmo; uma incitación, provocación"” (BANCO MUNDIAL, 2005, p. 7). Trata dos incentivos que devem ser utilizados para atrair novos professores e motivar aqueles que já exercem a profissão; contudo as orientações sugerem políticas que assegurem tais incentivos.

A preocupação com as políticas de formação de professores visa melhorar a qualidade do ensino e da aprendizagem. Se em épocas passadas a preocupação com a educação centrava-se no desenvolvimento de políticas de acesso, ou seja, no aumento do número de pessoas escolarizadas, o que implicava, portanto, na construção de mais escolas para ampliação de vagas, nos anos finais da década de 1990 e nos anos iniciais do século XXI essa preocupação deixou de ser prioritária e a questão primordial passou a ser a qualidade da educação ofertada.

A partir do momento em que a qualidade passou a ser o principal objetivo da educação os professores se tornaram elementos fundamentais nesse processo, pois embora não sejam os únicos responsáveis pela garantia de qualidade do processo de ensino aprendizagem, a eles destinou-se esse quesito como bassilar.

Há diferentes maneiras de incentivar um profissional da educação, que vão além de reajustes salariais. É preciso investir também na infraestrutura para criar um ambiente apropriado para o desenvolvimento do trabalho do professor. Conforme o discurso do BM (2005), os materiais didáticos, por exemplo, devem ser estudados pelo professor para que ele escolha qual o melhor método didático que se enquadra em seu trabalho.

O desenvolvimento da educação requer um profissional qualificado e um sistema unificado e igualitário, porém

[...] históricamente Brasil há sido uno dos países más descentralizados de la región, teniendo gobiernos estaduales y municiáles que manejan sistemas educacionales [...]. Este alto grado de descentralización se há traducido en una enorme desigualdad em los recursos disponibles para los sistemas educacionales $[. . .]^{10}$ (BANCO MUNDIAL, 2005, p. 12).

\footnotetext{
${ }^{9}$ Algo que desperta sentimentos ou incite à ação; Uma causa ou motivo de excitação; Uma incitação, uma provocação. (BANCO MUNDIAL, 2005, p. 7, tradução nossa).

${ }^{10} \mathrm{O}$ Brasil tem sido historicamente um dois países mais descentralizados na região, com os governos estaduais e os sistemas educacionais. Esse alto grau de descentralização resultou em enormes desigualdades de recursos disponíveis para os sistemas educativos. (BANCO MUNDIAL, 2005, p. 12, tradução nossa).
} 
Como reflexo dessa desigualdade, o incentivo à carreira de professor é desproporcional. O documento em questão relata que no Brasil uma solução apresentada para resolver essa desigualdade foi o estabelecimento, em nível federal, de que $60 \%$ dos recursos destinados à educação fossem investidos nos salários dos professores, pois esse fator motivaria aqueles que já atuam como professores e incentivaria novos sujeitos a seguirem essa carreira ${ }^{11}$.

De acordo com o documento Mejorar la enseñanza y el aprendizaje por medio de incentivos (2005), existem pelo menos sete componentes que influenciam na qualidade do ensino, a saber: "En primer lugar, los maestros deben tener acceso a materiales didácticos adecuados y contar com condiciones de infraestructura básicas" (BANCO MUNDIAL, 2005, p. 13). É necessário fornecer aos professores materiais com qualidade e um ambiente adequado para o desenvolvimento de seu trabalho. O espaço físico deve ser conforme a faixa etária do aluno, e os materiais didáticos precisam estar em conjunto com o conhecimento transmitido pelo professor.

O segundo componente aborda que é necessário que os professores tenham consciência de seu valor e de sua importância diante dos alunos e que estejam preparados para a jornada de trabalho que lhes espera "[...] los maestros deben saber qué se espera de ellos. [...]” (BANCO MUNDIAL, 2005, p. 14). Consta ainda no no segundo componente que um sistema que valoriza seu profissional é aquele que evidencia suas expectativas sobre esse profissional. Destacamos a necessidade de se especificar a forma de conduta que o professor precisa ter, bem como dar amparo pedagógico para que este realize seu trabalho com vistas ao rendimento do aluno. Sem explicações claras sobre o que se espera do professor, não é possível um trabalho com qualidade.

O terceiro componente destaca que o processo de contratação de professores afeta a qualidade do ensino e aprendizagem. Na perspectiva do BM, a influência das políticas são agravantes nesse processo, já que ao selecionar professores nem sempre estes encontram-se de acordo com as regras que devem cumprir ao lecionarem nas escolas para onde foram designados. Em alguns países, salienta o $\mathrm{BM}$, que o problema do sistema de contratação de professores é que aqueles que tem mais experiência são escolhidos para lecionarem em escolas com um grau de desenvolvimento maior. E consequentemente, as escolas onde há necessidade de um trabalho melhor elaborado são atribuídas aos professores com menos experiência.

O quarto componente diz respeito à prioridade do acompanhamento, por parte dos professores, dos resultados dos investimentos executados na educação, pois somente assim saberão se as expectativas neles depositadas são cumpridas.

\footnotetext{
${ }^{11}$ Essa ação se deu com a criação do Fundo de Manutenção e Desenvolvimento do Ensino Fundamental e de Valorização do Magistério - FUNDEF -, em 1996, pela Emenda Constitucional no 14 (BRASIL, 1996b) e regulamentação pela Lei 9.424/96 (BRASIL, 1996c).
} 
Segundo o documento, o conhecimento que os alunos adquirem é uma forma de avaliar o desempenho do professor.

O quinto componente enfatiza que:

[...] para enseñar bien, se requiere um aprendizaje continuo; para lograr que todos los alumnos aprendan, se requiere que los maestros de cada escuela trabajen en conjunto en el diseño de estrategias para cada alumno. Por lo tanto, si bien un sistema eficaz para atraer y retener a los buenos maestros es aquél en el cual existen claras expectativas con respecto a las competencias que deben tener los maestros y las conductas que deben exhibir y en el cual los maestros son monitoreados y evaluados en forma continua, tan esencial como ló anterior es la utilización de esta información para brindar a los maestros el apoyo técnico y directivo que requieren, junto con las oportunidades de desarrollo profesional necesarias para que tengam éxito en la tarea de generar el aprendizaje de los alumnos. ${ }^{12}$ (BANCO MUNDIAL, 2005, p. 15).

Esse quinto componente traz uma questão deveras relevante, pois para que haja um ensino contínuo é preciso muito mais do que a iniciativa dos professores de se comunicarem; é preciso o apoio de toda a equipe pedagógica. Compartilhar conhecimentos e experiências contribui para o desenvolvimento da educação, uma vez que a comunicação entre as escolas é essencial para que o ensino caminhe de maneira igualitária. Além disso, é de suma importância que os administradores da escola atribuam um tempo na carga horária do professor para que este possa se comunicar com os demais colegas, para que haja troca de informações e experiências, ou seja, disponibilizar ao professor um tempo para que ele busque novos conhecimentos, não somente na troca de informações com outros profissionais, mas oportunidades que façam com que os educadores adquiram novos conhecimentos e as repassem aos alunos.

O sexto componente traz que "[...] los maestros eficaces tienen autoridad para utilizar su mejor juicio profesional en la determinación de ló que se requiere pra obtener resultados en función de los estándares acordados"13 (BANCO MUNDIAL, 2005, p. 16). Esse componente sugere que com a autonomia de recursos, diretores e gestores das escolas devem gratificar os professores que apresentam um maior

\footnotetext{
${ }^{12}$ Para ensinar bem, é necessário um aprendizado contínuo a fim de garantir que todos os alunos aprendam,. Exige-se dos professores um trabalho conjunto com a escola na elaboração de estratégias para cada aluno. Portanto, um sistema eficaz para atrair e reter bons professores é aquele em que há expectativas claras sobre as habilidades e os comportamentos esperados dos professores e que devem ser exibidos na sua prática. Os professores são monitorados e avaliados continuamente, tão essencial como é o uso prévio de informações para fornecer aos professores, com o apoio técnico e gerencial necessário, juntamente com oportunidades de desenvolvimento profissional para o sucesso da tarefa de gerar aprendizagem escola. (BANCO MUNDIAL, 2005, p. 15, tradução nossa).

${ }^{13}$ Professores efetivos estão habilitados a usar o seu melhor julgamento profissional para determinar o que é necessário pra obter resultados com base em normas acordadas. (BANCO MUNDIAL, 2005, p. 16, tradução nossa).
} 
desempenho e punir aqueles professores cujo desenvolvimento não se destaca. Essa recomendação tem orientado o encaminhamento de políticas nacionais e internacionais e aqui no Brasil em nível nacional, estadual e municipal. Trata-se de uma forte tendência no que se refere à valorização dos professores.

E por fim, o sétimo componente apresenta elementos que deveriam ser relevantes ao elaborar uma política para atrair e incentivar aqueles que já exercem a profissão de professor.

Estas políticas podrían incluir ló seguinte: suelos relativos adecuados, es decir, sueldos que sean por lo menos tan altos como ofrecidos a las personas con similares características en otras profesiones; mejores sueldos para los maestros con un mejor desempeño; mejores sueldos para los maestros que trabajan em condiciones más difíciles (por ejemplo, zonas remotas, poblaciones desafavorecidas); una carrera docente bien definida, con oportunidades de promoción, reconocimiento público y prestigio para los maestros de excelência; una verdadera amenaza de perder el empleo como resultado de un desempeño inadecuado y una relación relativamente estrecha con el cliente, en la cual los maestros deban convencer regularmente a alguna persona (los directivos de los establecimientos, los padres o las comunidades) de que se están desempeñando de manera adecuada. ${ }^{14}$ (BANCO MUNDIAL, 2005, p. 16).

Esses elementos reforçam que os professores precisam ser conscientes de que eles constituem a peça fundamental para o desenvolvimento da educação. É função do sistema educacional esclarecer aos educadores que sem eles não é possível o progresso na educação, criar oportunidades para a sua qualificação, conscientizando-os de que são responsáveis e ao mesmo tempo incentivá-los e motivá-los em sua profissão.

Em todos os componentes referidos, o professor é descrito como um sujeito que deve ter consciência de seu papel na sociedade; para tanto, é preciso que haja uma conscientização nesse sentido de toda a equipe escolar. Maués (2003) adverte que os professores geralmente são tidos sempre como o alvo do fracasso escolar, sendo apontados ainda como o elemento principal em relação ao baixo rendimento escolar dos alunos e aos baixos índices de desenvolvimento da educação.

\footnotetext{
${ }^{14}$ Essas políticas poderão incluir: salários que são pelo menos tão alto quanto oferecidos a pessoas com características semelhantes em outras profissões; salários mais altos para os professores com melhor desempenho; salários mais altos para professores que trabalham em duras condições (por exemplo, áreas remotas, desfavorecidas); uma carreira docente bem definida, com oportunidades de promoção, reconhecimento público e prestígio para os professores de excelência; uma ameaça real de perder seus empregos como resultado de um desempenho inadequado e uma relação relativamente próxima com o cliente, em que os professores devem convencer ninguém regularmente (gerentes de estabelecimentos, os pais ou comunidades) que são desempenhadas adequadamente. (BANCO MUNDIAL, 2005, p. 16, tradução nossa).
} 
Vejamos, a seguir, o desdobramento dessas orientações do BM nas políticas para a formação de professores alfabetizadores no Brasil.

\section{Políticas educacionais brasileira para formação de professores: as interfaces com a formação de professores alfabetizadores}

A centralidade do papel dos professores na melhoria da qualidade da educação no Brasil tem sido discutida e amplamente defendida na atualidade por meio de diverso slogans, como "professores eficazes", "um bom professor, um bom começo". Intelectuais ${ }^{15}$ e representantes do terceiro setor, nomeadamente o Movimento Todos Pela Educação ${ }^{16}$ (TPE), apregoam que uma educação de qualidade depende exclusivamente da competência de seus professores.

É consenso que a Educação Básica precisa melhorar, pois tanto os defensores de uma escola focada no mercado quanto os defensores de uma educação como condição de emancipação humana reconhecem que ela não tem cumprido adequadamente o seu papel na sociedade.

No Brasil, muitas foram as políticas destinadas à formação e valorização de professores nos anos finais do século XX e neste início de século, período em que foram publicados os documentos do Banco Mundial aqui discutidos. É possível observarmos que as metas, as orientações estabelecidas pelo BM estão presentes nas leis, projetos e planos para a educação brasileiros.

No ano de 1996, foi elaborada a atual Lei de Diretrizes e Bases da Educação Nacional - Lei n ${ }^{\circ} 9.394 / 96$ em 2001, foi criado o Plano Nacional de Educação - Lei no 10.172/2001 ${ }^{17}$ - e também foram implantadas mudanças substanciais na Constituição Federal de 1988 por meio de Emendas Constitucionais, entre as quais a Emenda Constitucional no 14, de 1996 (BRASIL, 1996b). Todos esses documentos apontam a importância da formação e valorização dos professores.

A Emenda Constitucional no 14, de 1996, criou o Fundo de Manutenção e Desenvolvimento do Ensino Fundamental e de Valorização do Magistério, o FUNDEF.

A distribuição de responsabilidades e recursos entre os estados e seus municípios a ser concretizada com parte dos recursos definidos neste artigo, na forma do disposto no art. 211 da Constituição Federal, e assegurada mediante a criação, no âmbito de cada Estado e do Distrito Federal, de um Fundo de manutenção e

\footnotetext{
${ }^{15}$ Dentre eles, destacamos Bernadete Gatti (2010) e Maria Helena Guimarães de Castro (2000).

${ }^{16}$ Ver o documento: Justiça pela qualidade na educação (TPE, 2013).

${ }^{17}$ Doravante PNE/2001.
} 
desenvolvimento do ensino fundamental e de valorização do magistério, de natureza contábil. (BRASIL, 1996c, art. $5^{\circ}, \sqrt{ } 1^{\circ}$, grifo nosso).

Ainda no Artigo $5^{\circ}$ dessa Emenda, especificamente no $\int 5^{\circ}$, especificase que "uma proporção não inferior a sessenta por cento dos recursos de cada Fundo referido no $\int 1^{\circ}$ será destinada ao pagamento dos professores do ensino fundamental em efetivo exercício no magistério". O FUNDEF foi regulamentado pela Lei no 9.424 , de 1996, e esteve em vigor por dez anos no país, até 31 de dezembro de 2006.

Com a criação desse Fundo houve priorização dos recursos da educação para o Ensino Fundamental em detrimento das demais etadas da Educação Básica que também necessitavam de investimentos. Essa ação focalizou os recursos para a Educação Básica, que naquele contexto contemplava como obrigatório as séries inicias do Ensino Fundamental e o fundo destinava recursos exclusivamente para esta etapa.

A LDB no 9.394/96, atualmente em vigor ${ }^{18}$, tem como a valorização dos profissionais da educação escolar (Artigo $3^{\circ}$, capítulo VII). O Título VI dessa Lei é destinado aos profissionais da educação, o qual abrange os Artigos 61 a 67, nos quais é especificada a condição para ser professor no país, tanto da Educação Básica quanto do Ensino Superior, discorrendo acerca das condições para o exercício em funções de gestão, do modo como se dará a formação de professores no país, bem como a forma como será promovida a valorização de professores pelos sistemas de ensino. Há ênfase na formação continuada e a distância em detrimento da formação inicial presencial. Tal encaminhamento também é sugerido pelo BM aos países que recorrem a seus empréstimos.

Em 1997, foi publicada pelo Conselho Nacional de Educação a Resolução $n^{\circ}$ 03, aprovada pelo Conselho Pleno, que estabelece diretrizes para a elaboração dos Planos de Carreira e remuneração do magistério nos estados e municípios. Embora essa resolução tenha estabelecido a criação de planos de carreira para a promoção da valorização dos profissionais, muitos estados e municípios não a atenderam, pois como já assinalamos neste trabalho, os recursos do FUNDEF eram destinados somente aos professores do Ensino Fundamental e a Resolução estabelecia que os planos de carreira deveriam contemplar igualmente todos os professores da Educação Básica, ou seja, Educação Infantil, Ensino Fundamental e Ensino Médio, como prevê a LDB/96.

Como política de formação, salientamos, nesse período, os Parâmetros Curriculares Nacionais (1998); como decorrência, foram desenvolvidas várias ações de formação de professores em todo o país como os Parâmetros em Ação e o Programa Nacional de Formação de Professores Alfabetizadores - o PROFA.

\footnotetext{
${ }^{18}$ Ao longo desses anos de vigência da Lei foram feitas várias modificações no texto original aprovado em 1996.
} 
Em 2001, foi sancionada a Lei $n^{\circ} 10.172$, que aprova o Plano Nacional de Educação para o decênio de 2001 a 2010. Esse Plano deveria constituir uma política de Estado para o país, pois apresentava objetivos e metas a serem alcançados naquele período. Esses objetivos e metas estavam em consonância com as metas estabelecidas na Conferência Mundial de Educação para Todos que ocorreu em Jomtien, em 1990. (BRASIL, 2001).

O PNE (2001-2010) propagava que a valorização do professor deveria ocorrer por meio de uma "política global de magistério", o que implicava em uma simultaneidade da "formação inicial; as condições de trabalho, salário e carreira; formação continuada.” (BRASIL, 2001, p. 95). Destacava ainda que o professor é o agente principal da educação, e para que os alunos compreendam o conteúdo são necessários professores qualificados, que tenham domínio do conhecimento para repassar a estes. Nesse sentido, verificamos uma aproximação com as ideias postuladas pelo Banco Mundial nos dois documentos analisados nesta pesquisa.

O PNE (2001-2010) estabeleceu ainda as seguintes diretrizes para a formação dos profissionais da educação e sua valorização:

Os cursos de formação deverão obedecer, em quaisquer de seus níveis e modalidades, aos seguintes princípios: a) sólida formação teórica nos conteúdos específicos a serem ensinados na Educação Básica, bem como nos conteúdos especificamente pedagógicos; b) ampla formação cultural; c) atividade docente como foco formativo; d) contato com a realidade escolar desde o início até o final do curso, integrando a teoria à prática pedagógica; e) pesquisa como princípio formativo; f) domínio das novas tecnologias de comunicação e da informação e capacidade para integrá-las à prática do magistério; g) análise dos temas atuais da sociedade, da cultura e da economia; h) inclusão das questões relativas à educação dos alunos com necessidades especiais e das questões de gênero e de etnia nos programas de formação; i) trabalho coletivo interdisciplinar; j) vivência, durante o curso, de formas de gestão democrática do ensino; k) desenvolvimento do compromisso social e político do magistério; e l) conhecimento e aplicação das diretrizes curriculares nacionais dos níveis e modalidades da educação básica. (BRASIL, 2001, p. 98).

Entretanto, contraditoriamente, as políticas de formação de professores incentivadas e concretizadas ocorreram em um formato aligeirado, utilizando-se em grande medida dos recursos da tecnologia da educação a distância, o que parece não ter coerência com as Diretrizes apresentadas no PNE. A formação inicial dos professores deve ser oferecida por instituições de Ensino Superior e não necessariamente em universidades, onde há como pressuposto básico a indissociabilidade entre ensino, pesquisa e extensão. Como frisa do documento, a formação continuada dos professores da rede pública “[...] deverá ser garantida pelas secretarias estaduais e municipais da educação [...]” (BRASIL, 2001, p. 99). 
Em 2009, foi publicado pelo Ministério da Educação (MEC) e pelo Instituto Nacional de Estudos e Pesquisas Educacionais Anísio Teixeira (INEP) os resultados da pesquisa "Avaliação do Plano Nacional de Educação: desafios e perspectiva", coordenada por Luiz Fernando Dourado, que teve como objetivo avaliar os resultados alcançados pelo PNE (2001-2010). Essa pesquisa analisou os objetivos e metas de todos os níveis e modalidades da educação que constavam no plano, bem como os objetivos e metas destinados aos profissionais da educação. O resultado da pesquisa foi publicado em três volumes, no documento "Avaliação do Plano Nacional de Educação 2001-2008" e no volume três encontramos a avaliação do Magistério da Educação Básica, na qual são avaliadas a formação e a valorização dos professores nos oito anos de Plano. $\mathrm{Na}$ introdução do referido volume, podemos ler:

No âmbito das discussões, projetos e ações resultantes, destaca-se o Plano Nacional de Educação (PNE), aprovado pela Lei no 10.172 , de 09 de janeiro de 2001, que privilegia a melhoria da qualidade do ensino no Brasil como uma das principais metas. Com efeito, o documento consubstancia um conjunto de diretrizes e metas que, além de cobrir todas as etapas e modalidades de ensino dedica capítulos a temas transversais e/ou estratégicos, como financiamento, gestão e formação dos profissionais. (DOURADO, 2009, p. 599).

O objetivo desse documento é apontar quais ações o Ministério da Educação desenvolve para que o profissional professor que atua em sala de aula seja reconhecido e valorizado. Para tanto, o MEC procurou criar políticas de formação inicial e continuada aos professores a fim de que estes fossem qualificados para atuar em sala de aula. A esse respeito, citamos Dourado (2009, p. 600), para quem "A convicção geral é a de que a formação é fundamental para a profissionalização e valorização dos profissionais da educação e para a melhoria do processo ensino-aprendizagem".

O questionamento do MEC em relação à formação de professores é que, segundo esses profissionais, eles recebem uma formação baseada em concepções reducionistas, mas permanece a ênfase de que são propostas e projetos que visam favorecer uma sólida formação teórico-prática. As ações e projetos do Ministério da Educação contribuem para a "articulação entre teoria e prática", pois esse órgão considera que o professor sempre é um sujeito que mesmo já atuando em sala de aula, ainda se encontra em constante processo de formação. Ganham destaque também preocupações com a melhoria das condições de trabalho - salário, plano de carreira, política de capacitação e avaliação.

Dentre as ações do MEC na implementação de políticas e projetos, pontuamos algumas abordadas no documento, quais sejam: 
[..] a Rede Nacional de Formação Continuada de Professores (Rede); a lei do Piso Salarial profissional nacional, o Plano de Metas Compromisso Todos pela Educação; os projetos Educação em Direitos Humanos e Escola que Protege os programas Proinfantil, Prolicenciatura e Prouni; e a Universidade Aberta do Brasil (UAB). (DOURADO, 2009, p. 600).

A Rede Nacional de Formação Continuada de Professores constitui uma estratégia de formação e valorização docente e conta com a participação de instituições de Ensino Superior (IES) para a oferta de cursos de formação inicial e continuada. Essa formação se dá de maneira predominante por meio da educação a distância.

No ano de 2006, a vigência do FUNDEF chegou ao fim, dando lugar ao FUNDEB - Fundo de Manutenção e Desenvolvimento da Educação Básica e de Valorização dos Profissionais da Educação, criado pela EC no 53/06 (BRASIL, 2006) e regulamentado no ano seguinte pela Lei no 11.494/2007 (BRASIL, 2007a). O novo Fundo abrange a Educação Básica, que compreende a feixa etária de 4 a 17 anos, e foi implantado de forma progressiva entre os anos de 2007 a 2009. Sua validade é de 14 anos, portanto, vigorará até 31 de dezembro de 2020.

O Artigo $7^{\circ}$ da Lei n ${ }^{\circ} 11.494 / 2007$ estabelece que

Parcela da complementação da União, a ser fixada anualmente pela Comissão Intergovernamental de Financiamento para a Educação Básica de Qualidade instituída na forma da Seção II do Capítulo III desta Lei, limitada a até 10\% (dez por cento) de seu valor anual, poderá ser distribuída para os Fundos por meio de programas direcionados para a melhoria da qualidade da educação básica, na forma do regulamento. Parágrafo único. Para a distribuição da parcela de recursos da complementação a que se refere o caput deste artigo aos Fundos de âmbito estadual beneficiários da complementação nos termos do art. $4^{\circ}$ desta Lei, levar-se-á em consideração: [...] II - o desempenho do sistema de ensino no que se refere ao esforço de habilitação dos professores e aprendizagem dos educandos e melhoria do fluxo escolar; [...]. (BRASIL, 2007a).

Percebemos que os investimentos feitos na educação com os recursos desse Fundo consideram o desempenho dos professores como algo essencial para o desenvolvimento do ensino. Além disso, o Artigo 22 dessa Lei determina que pelo menos 60\% (sessenta por cento) dos recursos anuais totais dos Fundos sejam destinados ao pagamento da remuneração dos profissionais do magistério da Educação Básica em efetivo exercício na rede pública.

No Artigo 40 da Lei no 11.494/2007 é apresentada uma questão de grande relevância para os profissionais da educação: 
Art. 40. Os Estados, o Distrito Federal e os Municípios deverão implantar Planos de Carreira e remuneração dos profissionais da educação básica, de modo a assegurar: I - a remuneração condigna dos profissionais na educação básica da rede pública; II - integração entre o trabalho individual e a proposta pedagógica da escola; III - a melhoria da qualidade do ensino e da aprendizagem. (BRASIL, 2007a).

A Lei Lei no 11.494/2007 estabelece ainda que "O poder público deverá fixar, em lei específica, até 31 de agosto de 2007, piso salarial profissional nacional aos profissionais do magistério público da educação básica” (BRASIL, 2007a, Art. 41). Esse preceito legal foi cumprido com a aprovação da Lei $n^{\circ} 11.738$, de julho de 2008 (BRASIL, 2008). ${ }^{19}$

Além de estabelecer o valor mínimo a ser pago ao professor formado em nível médio, modalidade normal, por uma jornada de quarenta horas semanais, a Lei $n^{\circ} 11.738$ (BRASIL, 2008) estabelece também a carga horária de efetivo trabalho junto aos alunos $2 / 3$ (Artigo $2^{\circ}, \sqrt{5} 4^{\circ}$ ). Isso significa que a jornada destinada a estudos, planejamento (hora-atividade) será de $1 / 3$. A Lei reafirma também a incumbência da União, Estados, Distrito Federal e Municípios de elaborar ou adequar seus planos de carreira e remuneração do magistério (Artigo $6^{\circ}$ ).

Em 2007, foi lançado o Plano de Desenvolvimento da Educação (PDE), que prevê um conjunto de ações em parceria com os entes federados, instituições de ensino superior e organizações da sociedade civil para mobilizar os esforços e as capacidades em favor de uma educação de qualidade (DOURADO, 2009). Entre essas ações, destacamos os programas de formação de professores, tanto formação inicial quanto formação continuada. Tal ênfase se dá pela crença de que o papel do professor é de fundamental importância para a promoção da melhoria da educação.

No mesmo ano, foi proposto pelo Decreto $n^{\circ}$ 6.094, de 24 de abril de 2007, o Plano de Metas Compromisso Todos pela Educação (BRASIL, 2007b), que objetiva a mobilização social pela melhoria da qualidade da Educação Básica. Observamos, nas estratégias, a forte marca das orientações do Banco Mundial. Há também uma tendência a rever ou relativizar a estabilidade dos professores na rede pública aprovados por concurso público, ou seja, sugere-se que a garantia do emprego seja por meio do desempenho na função, verificado por meio de avaliações externas.

\footnotetext{
${ }^{19}$ Uma Ação Direta de Inconstitucionalidade (ADI n ${ }^{\circ}$ 4.167/2008) foi impetrada junto ao Supremo Tribunal Federal por cinco Estados brasileiros, entre eles o Estado do Paraná, na qual se questionava a constitucionalidade da Lei recém-aprovada. A decisão do STF só saiu em 2011, na qual foi afirmada sua constitucionalidade e o imediato cumprimento da Lei pelos Estados e Municípios. Na Lei, constava ainda que o piso salarial nacional para os profissionais do magistério públicos da Educação Básica seria de R \$ 950,00 (Artigo $2^{\circ}$ ). Atualmente, o valor do piso é de $\mathrm{R} \$ 1.567,00$.
} 
Outro documento de grande relevância para os profissionais da educação é o Decreto $n^{\circ}$ 6.755, de 29 de janeiro de 2009, que institui a Política Nacional de Formação de Profissionais do Magistério da Educação Básica:

Art. $1^{\circ}$ Fica instituída a Política Nacional de Formação de Profissionais do Magistério da Educação Básica, com a finalidade de organizar, em regime de colaboração entre a União, os Estados, o Distrito Federal e os Municípios, a formação inicial e continuada dos profissionais do magistério para as redes públicas da educação básica. (BRASIL, 2009).

Entre os vários objetivos da política apresentados no Decreto, o primeiro refere-se à promoção da melhoria da qualidade da Educação Básica pública (Artigo $3^{\circ}$, inciso I). Notamos, portanto, que a questão essencial é melhorar a qualidade da educação, e se para tanto são consideradas primordiais a formação e a valorização dos professores, políticas e ações nesse sentido serão propostas pelos governos.

Conforme o Decreto, o fomento a programas de formação inicial e continuada é de responsabilidade da Coordenação de Aperfeiçoamento de Pessoal de Nível Superior (Capes). O Decreto prevê também a criação de Fóruns Estaduais de Apoio à Formação dos Profissionais da Educação e ainda programas de iniciação à docência nos curso de licenciatura de graduação plena nas instituições de Ensino Superior (BRASIL, 2009, Artigo 10). Trata-se de uma aproximação do Ensino Superior com a Educação Básica com o intuito de promover melhorias na qualidade do processo de ensino e aprendizagem e, consequentemente, aumentar os índices educacionais.

Em 30 de junho de 2009, foi publicada a Portaria Normativa $n^{\circ}$ 9, do Ministério da Educação, que instituiu o Plano Nacional de Formação dos Professores da Educação Básica (PARFOR). Esse Plano tem como objetivo estabelecer ações e metas para a qualificação dos 600 mil professores brasileiros que ainda não possuem a formação considerada adequada ao trabalho que exercem e faz parte das ações previstas na Política Nacional de Formação dos Profissionais do Magistério para a Educação Básica. (BRASIL/MEC, 2009).

Destacamos ainda, como ações do executivo federal, a Conferência Nacional de Educação (CONAE) ocorrida entre os dias 28 de março a 1 de abril de 2010. Precederam à conferência nacional várias conferências municipais, intermunicipais, estaduais e interestaduais, com participação ampla de representações da sociedade em geral. A construção de um sistema nacional articulado de educação e a elaboração do novo Plano Nacional de Educação foram os temas centrais da Conferência.

Como decorrência dessa Conferência, tramitou no Congresso Nacional o Projeto de Lei no 8.035/2010 (BRASIL, 2010), que estabeleceu o atual Plano 
Nacional de Educação, Lei no 13.005/2014 (BRASIL, 2014). A valorização dos profissionais da educação no atual PNE é apresentada como um dos principais problemas e desafios para que o país tenha uma educação de qualidade. As estratégias trazidas pelo PNE (2014) procuram incentivar a formação de professores; entre suas muitas estratégias e metas, ressaltamos algumas:

4.3) implantar, ao longo deste PNE, salas de recursos multifuncionais e fomentar a formação continuada de professores e professoras para o atendimento educacional especializado nas escolas urbanas, do campo, indígenas e de comunidades quilombolas; [...] 5.6) promover e estimular a formação inicial e continuada de professores (as) para a alfabetização de crianças, com o conhecimento de novas tecnologias educacionais e práticas pedagógicas inovadoras, estimulando a articulação entre programas de pós-graduação stricto sensu e ações de formação continuada de professores (as) para a alfabetização. (BRASIL, 2014).

O novo Plano Nacional de Educação, que entrou em vigor com a Lei ${ }^{\circ}$ 13.005/2014 (BRASIL, 2014), apresenta velhos problemas e desafios que o Estado e a sociedade busca sanar ao longo de décadas. Desde a Constituição Federal de 1988 é apresentado como um princípio a valorização dos profissionais da educação por meio da elaboração de Planos de Carreira e Remuneração do Magistério, no entanto, ainda são muitos os Estados e Municípios que não os têm ou não o adequaram para que de fato promovam-se tal valorização.

No campo da formação de professores alfabetizadores no Brasil, durante o período de abrangência desta pesquisa destacamos em nossas análises os programas de formação Pró-Letramento e Pacto Nacional pela Alfabetização na Idade Certa. De acordo com o portal do Ministério da Educação, o Pró-Letramento foi um programa de formação continuada de professores para a melhoria da qualidade de aprendizagem da leitura/escrita e matemática nos anos/séries iniciais do ensino fundamental. Esse programa teve parceria com universidades e unificou a Rede Nacional de Formação Continuada com Estados e Munícipios. Participaram do Pró-Letramento (2010) professores das séries iniciais do Ensino Fundamental da rede pública. O Pró-Letramento funcionou como uma modalidade semipresencial. Utilizava-se de material impresso e em vídeo, atividades presenciais e a distância eram acompanhadas por professores orientadores, também chamados de tutores. Os cursos de formação continuada oferecidos pelo programa teve duração de 120 horas com encontros presenciais e atividades individuais com duração de 8 meses.

O Pró-Letramento (2010) teve como objetivo oferecer suporte aos professores das séries iniciais do Ensino Fundamental no que diz respeito à leitura e à escrita, propondo situações que incentivassem os professores a refletir sobre a construção do desenvolvimento de seu trabalho, além de contribuir para o desenvolvimento da matemática e da linguagem e desencadear ações de formação 
continuada em rede, envolvendo universidades, secretarias de educação e escolas públicas dos sistemas de ensino (MEC).

Na acepção de Moreira e Saito (2013, p. 62), esse programa, assim como o atual Pacto Nacional pela Alfabetização na Idade Certa, se estabeleceram pelo "[...] envolvimento das universidades com as demais instituições e entes federados que assumiram o compromisso da alfabetização e letramento das crianças brasileiras, matriculadas nos anos iniciais do ensino fundamental". As autoras chamam a atenção para alguns desafios que permamecem no que concerne à formação de professores alfabetizadores. No Pró-Letramento (2010), os desafios se centraram no âmbito ds políticas desconectadas e na falta de conciliação entre os entes federativos.

Tanto o Pró-Letramento quanto o PNAIC são programas que necessitam do regime de colaboração entre os entes federados para o seu eficaz funcionamento. Para isso, o desafio de proporcionar sua efetivação com qualidade e duração prolongada envolve uma contínua gestão, o que muitas vezes não ocorre mediante a troca das gestões governamentais nas esferas.

Atualmente, o Pacto Nacional Pela Alfabetização na Idade Certa (20132014), também proposto pelo Ministério da Educação, tem por objetivo formar professores do ciclo de alfabetização, visando a organizar o processo pedagógico da alfabetização escolar e possibilitar, assim, o desenvolvimento da aquisição da escrita e da leitura às crianças (MOREIRA; SAITO, 2013). Frisamos quatro princípios centrais no trabalho pedagógico desenvolvido no PNAIC:

1. o Sistema de Escrita Alfabética é complexo e exige um ensino sistemático e problematizador;

2. o desenvolvimento das capacidades de leitura e de produção de textos ocorre durante todo o processo de escolarização, mas deve ser iniciado logo no início da Educação Básica, garantindo acesso precoce a gêneros discursivos de circulação social e a situações de interação em que as crianças se reconheçam como protagonistas de suas próprias histórias;

3. conhecimentos oriundos das diferentes áreas podem e devem ser apropriados pelas crianças, de modo que elas possam ouvir, falar, ler, escrever sobre temas diversos e agir na sociedade;

4. a ludicidade e o cuidado com as crianças são condições básicas nos processos de ensino e de aprendizagem. (MEC, 2015, p. 1).

A filosofia permeada nas formações realizadas no Pacto Nacional Pela Alfabetização na Idade Certa (2013-2014) centra-se na clareza do que se ensina e de como se ensina no processo de alfabetização e letramento. 


\section{À guisa de conclusão}

As políticas para a formação de professores desenvolvidas no Brasil nos últimos anos, como vimos neste artigo, se encontram em sintonia com as recomendações dos organismos internacionais, nomeadamente o BM.

Observamos também que o Plano Nacional de Educação (2001-2010) não alcançou a totalidade dos objetivos, metas e estratégias traçadas. Nesse sentido, o novo Plano Nacional de Educação (2014-2024) idealiza e estabelece novas metas e estratégias para dar continuidade ao processo de melhoria da qualidade da educação com o fito de alavancar os baixos resultados que a educação brasileira apresentou para que sejam banidos os atrasos que ao longo da história ainda permanecem.

Ao finalizar destacamos ainda que os atuais programas de formação de professores no campo da alfabetização e letramento trouxeram muitos desafios, dentre os quais a retomada da formação continuada no âmbito da universidade. Todavia, salentamos que permanece ainda o desafio da realização dessa formação permanente em uma perspectiva interdisciplinar, em rede, por meio do desafio contínuo do regime de colaboração entre os entes federados. Para o desenvolvimento adequado desta proposta de formação continuada nos atuais programas, necessita-se das condições como o tempo prioritário para isso, a viabilização do transporte e todas as condições necessárias para o deslocamento dos professores até o local onde se desenvolve a formação.

\section{Referências}

BANCO MUNDIAL. Prioridades y estrategias para la educacion: examen del Banco Mundial. Washington, 1995.

BANCO MUNDIAL. Mejorar la enseñanza y el aprendizaje por médio de incentivos: qué lecciones nos entregan lãs reformas educativas de América Latina? Washington, 2005.

BRASIL. Constituição da República Federativa do Brasil. São Paulo: Imprensa Oficial do Estado, 1988.

BRASIL. Lei no 9.394, de 20 de dezembro de 1996. Estabelece as diretrizes e bases da educação nacional. Diário Oficial da União, Brasília, 23 dez. 1996a.

BRASIL. Emenda Constitucional no 14, de 12 de setembro de 1996. Modifica os arts. 34, 208, 211 e 212 da Constituição Federal e dá nova redação ao art. 60 do Ato das Disposições constitucionais Transitórias. Diário Oficial da União, Brasilia, 13 set. 1996b.

BRASIL. Lei n ${ }^{\circ}$ 9.424, de 24 de dezembro de 1996. Dispõe sobre o Fundo de Manutenção e Desenvolvimento do Ensino Fundamental e de Valorização do Magistério, na forma prevista no art. $60, \mathbb{\$} 7^{\circ}$, do Ato das Disposições Constitucionais Transitórias, e dá outras providências. Diário Oficial da União, Brasília, 26 dez. 1996c.

BRASIL. Lei no 10.172, de 9 de janeiro de 2001. Aprova o Plano Nacional de Educação e dá outras providências. Diário Oficial da União, Brasília, 10 jan. 2001. 
BRASIL. Emenda Constitucional n ${ }^{\circ}$ 53, de 19 de dezembro de 2006. Dá nova redação aos arts. $7^{\circ}, 23,30,206,208,211$ e 212 da Constituição Federal e ao art. 60 do Ato das Disposições Constitucionais Transitórias. Diário Oficial da União, Brasília, 20 dez. 2006.

BRASIL. Lei no 11.494, de 20 de junho de 2007. Regulamenta o Fundo de Manutenção e Desenvolvimento da Educação Básica e de Valorização dos Profissionais da Educação FUNDEB, de que trata o art. 60 do Ato das Disposições Constitucionais Transitórias; altera a Lei no 10.195, de 14 de fevereiro de 2001; revoga dispositivos das Leis nos 9.424, de 24 de dezembro de 1996, 10.880, de 9 de junho de 2004, e 10.845, de 5 de março de 2004; e dá outras providências. Diário Oficial da União, Brasília, 21 jun. $2007 \mathrm{a}$.

BRASIL. Decreto $n^{\circ}$ 6.094, de 24 de abril de 2007. Dispõe sobre a implementação do Plano de Metas Compromisso Todos pela Educação, pela União Federal, em regime de colaboração com Municípios, Distrito Federal e Estados, e a participação das famílias e da comunidade, mediante programas e ações de assistência técnica e financeira, visando a mobilização social pela melhoria da qualidade da educação básica. Diário Oficial da União, Brasília, 25 abr. 2007b.

BRASIL. Lei n ${ }^{\circ} 11.738$, de 16 de julho de 2008. Regulamenta a alínea "e" do inciso III do caput do art. 60 do Ato das Disposições Constitucionais Transitórias, para instituir o piso salarial profissional nacional para os profissionais do magistério público da educação básica. Diário Oficial da União, Brasília, 17 jul. 2008.

BRASIL. Decreto n ${ }^{\circ} 6.755$, de 29 de janeiro de 2009. Institui a Política Nacional de Formação de Profissionais do Magistério da Educação Básica, disciplina a atuação da Coordenação de Aperfeiçoamento de Pessoal de Nível Superior - CAPES no fomento a programas de formação inicial e continuada, e dá outras providências. Diário Oficial da União, Brasília, 30 jan. 2009.

BRASIL. Projeto de Lei n ${ }^{\mathbf{8}} \mathbf{8 . 0 3 5} / \mathbf{2 0 1 0}$. Aprova o Plano Nacional de Educação para o decênio 2011-2020 e dá outras providências. Brasília, 20 dez. 2010.

BRASIL. Lei ñ 13.005, de 25 de junho de 2014. Aprova o Plano Nacional de Educação - PNE e dá outras providências. Diário Oficial da União, Brasília, 26 jun. 2014.

BRASIL/MEC. Portaria Normativa no 09 de 30 de junho de 2009. Institui o Plano Nacional de Formação dos Professores da Educação Básica no âmbito do Ministério da Educação. Diário Oficial da União, Brasília , 1 jul. 2009. Seção 1. p. 9.

CARDOZO, M. J. P. B. Crise do capital: ajuste estrutural e as reformas educacionais propostas pelo Banco Mundial. In: JORNADA INTERNACIONAL DE POLÍTICAS PÚBLICAS, 2. 2005, São Luís. Anais... São Luís: UFMA, 2005. p. 1-9. Disponível em: <http:/ /www.joinpp. ufma.br/jornadas/joinppIII/html/Trabalhos2/Maria_Jos\%C3\%A9_Pires_BarrosCardozo215. pdf>. Acesso em: 5 jul. 2015.

CASTRO, M. H. G. Sistemas nacionais de avaliação e de informações educacionais. Revista Perspectiva, v. 14, n. 1, jan./mar. 2000. DOI: 10.1590/S0102-88392000000100014

DALE, R. Globalização e educação: demonstrando a existência de uma "cultura educacional mundial comum" ou localizando uma "agenda globalmente estruturada para a educação"? Educação \& Sociedade, Campinas, v. 25, n. 85, p. 423-460, maio/ago. 2004. DOI: 10.1590 / S0101-73302004000200007

DOURADO, L. F. (Coord.). Avaliação do Plano Nacional de Educação 2001-2008. Brasília: INEP, 2009. v. 3. p. 595-661. 
FONSECA, M. O Financiamento do Banco Mundial à educação brasileira: vinte anos de cooperação internacional. In: TOMMASI, L. de; WARDE, M. J.; HADDAD, S. O Banco Mundial e as políticas educacionais. São Paulo: Cortez, 1998. p. 229-251.

GATTI, B. Formação de professores no Brasil: características e problemas. Educação \& Sociedade, Campinas, v. 31, n. 113. p. 1355-1379, out./dez. 2010. DOI: 10.1590/S010173302010000400016

MAUÉS, O. C. Reformas internacionais da educação e formação de professores. Cadernos de Pesquisa, São Paulo, n. 118, p. 89-117, mar. 2003. DOI: 10.1590/S0100-15742003000100005

MEC. Entendendo o Pacto. 2015. Disponível em < http://pacto.mec.gov.br/component/ content/article?id=53:entendento-o-pacto $>$. Acesso em: 5 jul. 2015.

MOREIRA, J. A. da S. Políticas de financiamento e gestão da educação básica (19902010): os casos Brasil e Portugal. 2012. 357 f. Tese (Doutorado em Educação) - Universidade Estadual de Maringá, Maringá, 2012.

MOREIRA, J. A. da S.; SAITO, H. I. Da erradicação do analfabetismo ao compromisso de alfabetizar na idade certa: rumo a uma política nacional para alfabetização escolar? Revista Teoria e Prática da Educação, Maringá, v. 16, n. 3, p. 55-64, set./dez. 2013.

PEREIRA, J. M. M. O Banco Mundial como ator político, intelectual e financeiro (19442008). Rio de Janeiro: Civilização Brasileira, 2010.

SANDRONI, P. Dicionário de Economia. São Paulo: Abril Cultural, 1985.

SHIROMA, E. O.; MORAES, M. C. M.; EVANGELISTA, O. Política educacional. Rio de Janeiro: DP\&A, 2002.

SOARES, M. C. C. Banco Mundial: políticas e reformas. In: TOMMASI, L. de; WARDE, M. J.; HADDAD, S. (Orgs.). O Banco Mundial e as políticas educacionais. São Paulo: Cortez, 1998. p. 15-39.

TEODORO, A. Novos modos de regulação transnacional de políticas educativas. Evidências e possibilidades. In: TEODORO, A. (Org.). Tempos e andamentos nas políticas de educação: estudos iberoamericanos. Brasília: Líber Livro; CYTED, 2008. p. 19-38.

TOMMASI, L. de. Financiamento do Banco Mundial no setor educacional brasileiro: os projetos em fase de implantação. In: TOMMASI, L. de; WARDE, M. J.; HADDAD, S. (Orgs.). O Banco Mundial e as políticas educacionais. São Paulo: Cortez, 1998. p. 195-227.

TORRES, R. M. Melhorar a qualidade da educação básica? As estratégias do Banco Mundial. In: TOMMASI, L. de; WARDE, M. J.; HADDAD, S. (Orgs.). O Banco Mundial e as políticas educacionais. São Paulo: Cortez, 1998. p. 125-193.

TPE. Justiça pela qualidade da educação. 2013. Diaponível em <http://www. todospelaeducacao.org.br//arquivos/biblioteca/01_justica.pdf>. Acesso em: 10 out. 2015.

Recebido em 10/11/2014

Aceito em 20/07/2015 